\title{
Titanium sinter as gas diffusion backing in PEMFC
}

\author{
T. Hottinen", M. Mikkola, T. Mennola, P. Lund \\ Laboratory of Advanced Energy Systems, Helsinki University of Technology, \\ P.O. Box 2200, Fin-02015 HUT, Helsinki, Finland
}

\begin{abstract}
The use of a titanium sinter material as gas diffusion backing (GDB) in a polymer electrolyte membrane fuel cell (PEMFC) has been evaluated. The study focused on reducing the high contact resistance between the sinter and MEA using platinum and carbon coatings evaporated on the surface of the sinter. The results show that the titanium sinters are a promising solution for gas diffusion backing in a fuel cell and that the initially high contact resistance observed can be effectively reduced with platinum coating. The coatings also reduce the mass diffusion overpotential observed with the sinter.
\end{abstract}

(C) 2003 Elsevier Science B.V. All rights reserved.

Keywords: PEMFC; Titanium sinter; Gas diffusion backing; Contact resistance

\section{Introduction}

Polymer electrolyte membrane fuel cells (PEMFCs) are an intensively studied alternative for clean power production in several applications. The most studied fields are largescale applications such as transportation and distributed power generation. Small-scale applications, such as portable electronics, have received considerably less interest until recently. In order to make small-scale fuel cells competitive against battery technologies, the performance of the fuel cells, especially in terms of power density, has to be improved.

One of the main disadvantages in small-scale fuel cells compared to battery technologies is the need of auxiliary devices, such as mass-flow controllers, thermal management systems, and gas compressors or fans. In order to increase the power density of a fuel cell and to simplify the system structure, the number and power consumption of these auxiliary devices has to be minimized. One solution for this may be the use of ambient air for providing the oxygen needed by the fuel cell reaction. This can be accomplished by free-breathing fuel cells in which the cathode gas channels are open to ambient air [1-3] or in which there are no cathode gas channels at all. In the latter case, the oxygen is delivered to the reaction place through a metal grid or foam that is in direct contact with ambient air. This

\footnotetext{
* Corresponding author. Tel.: +358-9-451-3209; fax: +358-9-451-3195. E-mail address: tero.hottinen@hut.fi (T. Hottinen).
}

kind of approach in fuel cells that have forced oxygen feed is studied [4,5]. Sintered materials can be used as a direct gas diffusion path for oxygen from ambient air. This kind of approach using sintered stainless steel is presented in [6].

Sintered metal structures may also be advantageous in fuel cells that have forced air feed. The sinters have good mechanical strength and ductility. The geometry of the flow-field plates can be greatly simplified, because no ridges are needed to offer mechanical support for the gas diffusion backing as is the case with carbon paper. Another advantage with sinters is that the gas channels may be formed directly into the sinter during the sintering process [6]. This simplifies the cell structure since the sinter may operate as a combined gas diffusion backing/flowfield plate. Furthermore, the porosity of the sinter is not reduced as the fuel cell is compressed together. Excessive compression of carbon paper gas diffusion backing has been shown to increase the mass diffusion overpotential, which is suggested to result from the loss of porosity [7].

In order to be able to use sinter material as a gas diffusion backing or direct path for oxygen from ambient air, the usability of it in a fuel cell must be verified. In this study, a titanium sinter was used as gas diffusion backing in a PEMFC that has forced oxygen feed and the gas channels are not open to ambient air. The study concentrates on evaluating the usability of titanium sinter in a fuel cell and reducing the high contact resistance observed between the titanium sinter and MEA. 


\section{Experimental}

\subsection{Measurement procedure}

The measurements were performed with a fuel cell having an active area of $25 \mathrm{~cm}^{2}$. The fuel cell components used in the measurements, if not mentioned otherwise, are listed in Table 1. The measurements were conducted using a GT-100 fuel cell test station made by GlobeTech Inc. A PC was used to control the test station and to record the measurement data. A schematic of the measurement system is illustrated in Fig. 1.

Dry hydrogen was fed to the anode and dry oxygen to the cathode from pressure bottles. The measurements were conducted at a constant temperature of $50{ }^{\circ} \mathrm{C}$ and at ambient pressure. The end plates of the fuel cell were compressed together with torque of $2.5 \mathrm{~N} \mathrm{~m}$. The flow-rates in all measurements were $0.0261 \mathrm{~min}^{-1}+0.011 \mathrm{~A}^{-1} \mathrm{~min}^{-1}$ for hydrogen and $0.0621 \mathrm{~min}^{-1}+0.0251 \mathrm{~A}^{-1} \mathrm{~min}^{-1}$ for oxygen.

The polarization curves used for the performance characterization were obtained by scanning the current in linear steps of $16 \mathrm{~mA} \mathrm{~cm}^{-2}$ and simultaneously measuring the voltage of a fuel cell. The voltage was allowed to stabilize for $30 \mathrm{~s}$ at each measurement point before the next current step. The fuel cell was allowed to stabilize for $20 \mathrm{~min}$ at a current density of $100 \mathrm{~mA} \mathrm{~cm}^{-2}$ before the polarization curve was measured in order to achieve similar conditions for each measurement. The resistance of the fuel cell was measured simultaneously with the polarization curves using the current interruption feature built in the test station.

\subsection{Titanium sinters}

The sinters used in the measurements were $5 \mathrm{~cm} \times 5 \mathrm{~cm}$ in size and $0.5 \mathrm{~mm}$ thick. The porosity of each sinter was about $55 \%$ of the total volume. A light microscope image of an uncoated sinter with an indication of scale is illustrated in Fig. 2.

In order to reduce the contact resistance between the sinter and MEA, different coatings were applied on the surface of the sinter that is in contact with the MEA. Platinum coatings of 5 and $10 \mathrm{~nm}$ thickness and a carbon coating of $10 \mathrm{~nm}$ were prepared on the sinters by evaporation. A light microscope image of the titanium sinter with a $10 \mathrm{~nm}$ platinum coating is illustrated in Fig. 3. The platinum coating makes the

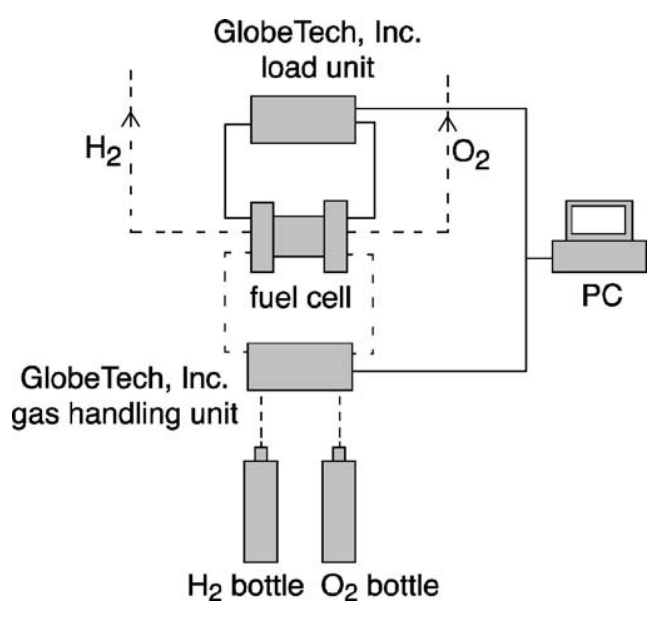

Fig. 1. The measurement system.

surface of the sinter brighter than that of an uncoated one. One can also see that the small scores on the sinter surface have become slightly smoother.

\section{Results}

The polarization curve measured with carbon paper as gas diffusion backing on both sides of the fuel cell was used as a reference to judge the performance of the titanium sinter. This polarization curve was compared to polarization curves obtained with titanium sinter on the anode and on the cathode. The other gas diffusion backing was carbon paper in both of these measurements. The comparison is illustrated in Fig. 4. The IR-compensated polarization and resistance curves of these three measurements are shown in Fig. 5. The IR-compensated polarization curve is calculated using equation

$E_{\mathrm{comp}}=E+I R$

where $E_{\mathrm{comp}}$ is the compensated voltage, $E$ the voltage of the fuel cell, $I$ the current taken from the fuel cell, and $R$ the resistance of the fuel cell.

Titanium sinter performs clearly weaker than carbon paper as can be seen in Fig. 4. Sinter on the anode side has slightly better performance than sinter on the cathode. The main reason for the poor performance can be seen from Fig. 5. The resistance of the fuel cell with titanium sinter as

Table 1

Fuel cell components used in the measurements

\begin{tabular}{lll}
\hline Component & Description & Manufacturer \\
\hline Combined end plates/current collectors & $1 \mathrm{~cm}$ thick gold-plated copper plate & GlobeTech Inc., modified by the authors \\
Flow-field plates & $\begin{array}{l}\text { Machined graphite plate for } 25 \mathrm{~cm}^{2} \\
\text { fuel cell, column flow pattern }\end{array}$ & GlobeTech Inc. \\
Anode side gas diffusion backing & Carbon paper, ${ }^{\circledR}$ SIGRACET GDL10-BB & SGL Technologies GmbH/SGL CARBON GROUP \\
MEA & PRIMEA ${ }^{\circledR}$ MEA Series 5510 & W.L. Gore and Associates \\
Cathode side gas diffusion backing & 0.5 mm thick titanium sinter & Research Centre of Powder Materials Science \\
\hline
\end{tabular}




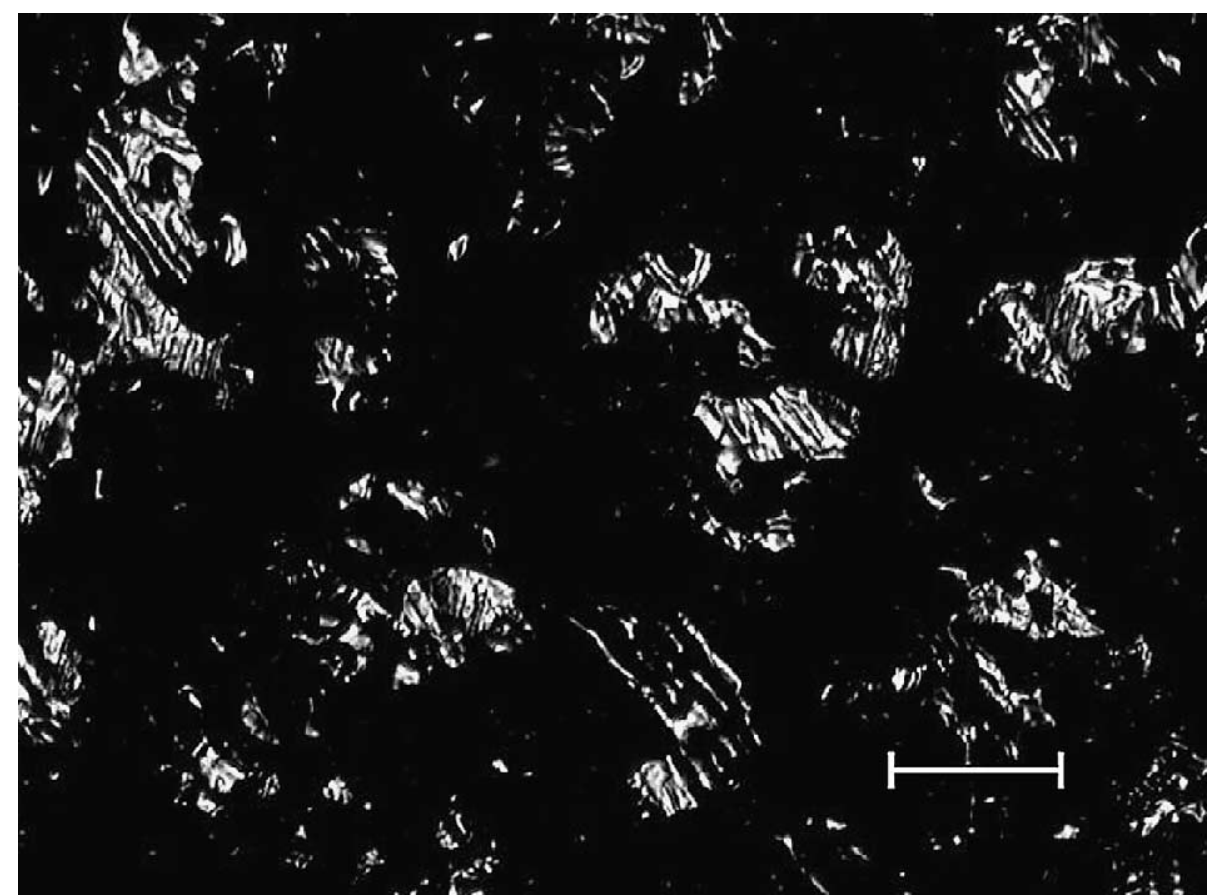

Fig. 2. Light microscope image of the surface of an uncoated titanium sinter. The length of the scale bar is $100 \mu \mathrm{m}$.

the gas diffusion backing is more than six times higher than the one with carbon paper. This is most probably due to high contact resistance between the sinter and MEA.

It can be seen from the IR-compensated polarization curves in Fig. 5 that the sinter on the anode causes almost no additional mass diffusion overpotential compared to the carbon paper. However, the sinter on the cathode clearly causes some mass diffusion problems. This may be due to insufficient removal of the excess water from the cathode. Oxygen and water move along the same passages in the sinter and thus the excess water blocks the oxygen's path to the reaction site. In this respect, sinters are slightly different from carbon papers and cloths. It has been suggested that in carbon paper the oxygen moves along the macropores

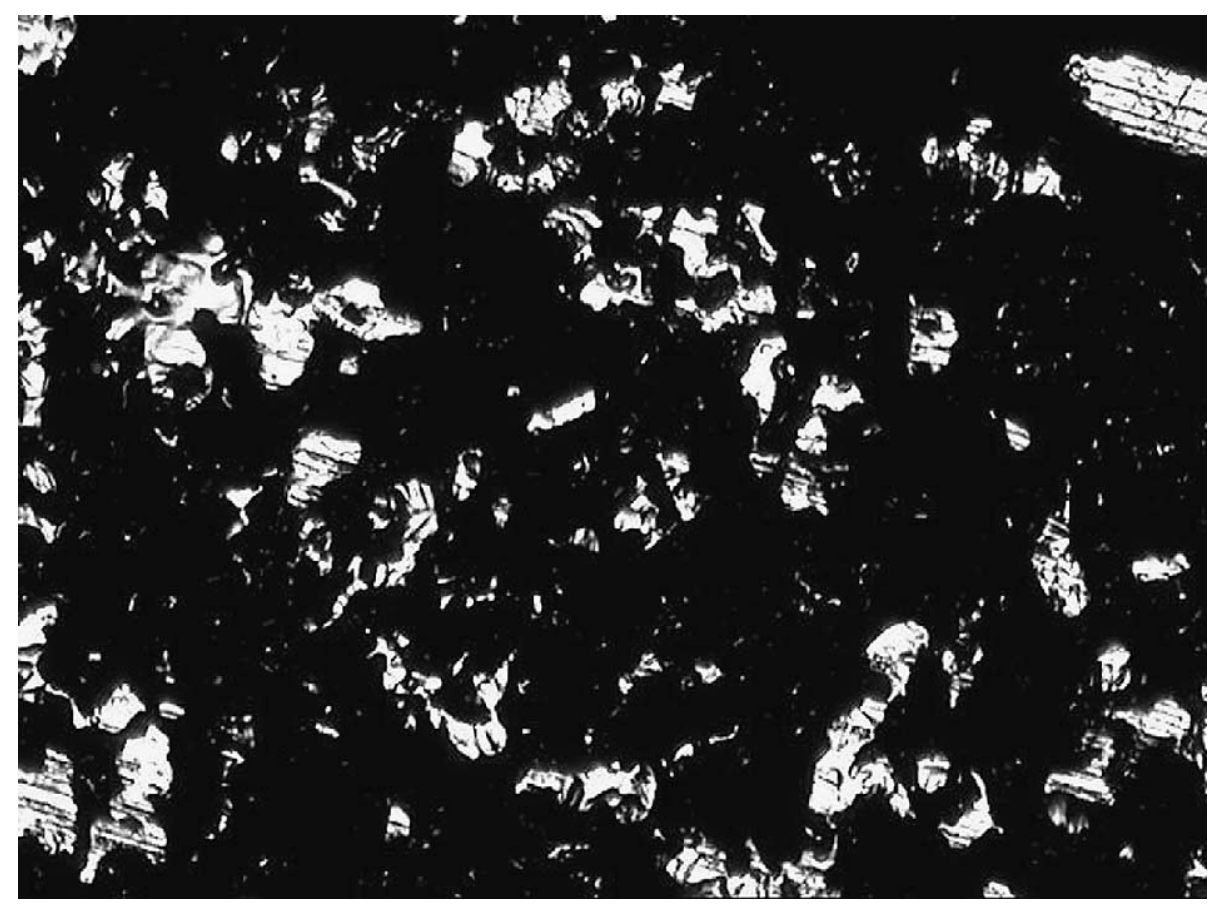

Fig. 3. Light microscope image of the surface of platinum-coated $(10 \mathrm{~nm})$ sinter. 


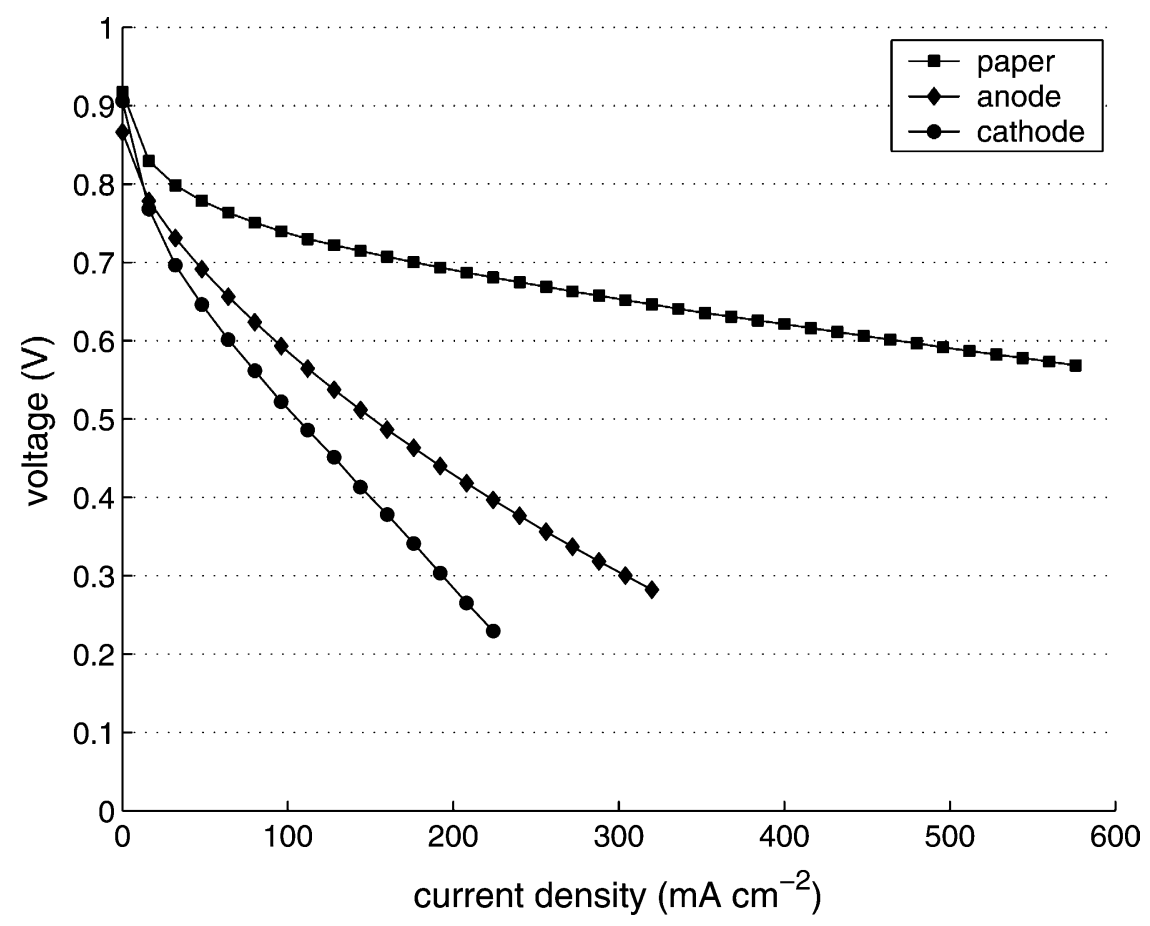

Fig. 4. The polarization curves from the measurement where both of the gas diffusion backings were carbon paper, and the measurements where other gas diffusion backing was titanium sinter: 'paper' refers to the measurement using carbon paper GDBs; 'anode' and 'cathode' indicate the location of the sinter GDB.

between carbon fibers, whereas the product water is transported in the micropores within carbon fibers by the capillary action [8]. The different passages reduce the blocking of the oxygen paths caused by product water.
The polarization curves of the measurements in which the platinum- and carbon-coated sinters were on the cathode are presented in Fig. 6. The corresponding IR-compensated polarization curves and resistance curves are given in Fig. 7.

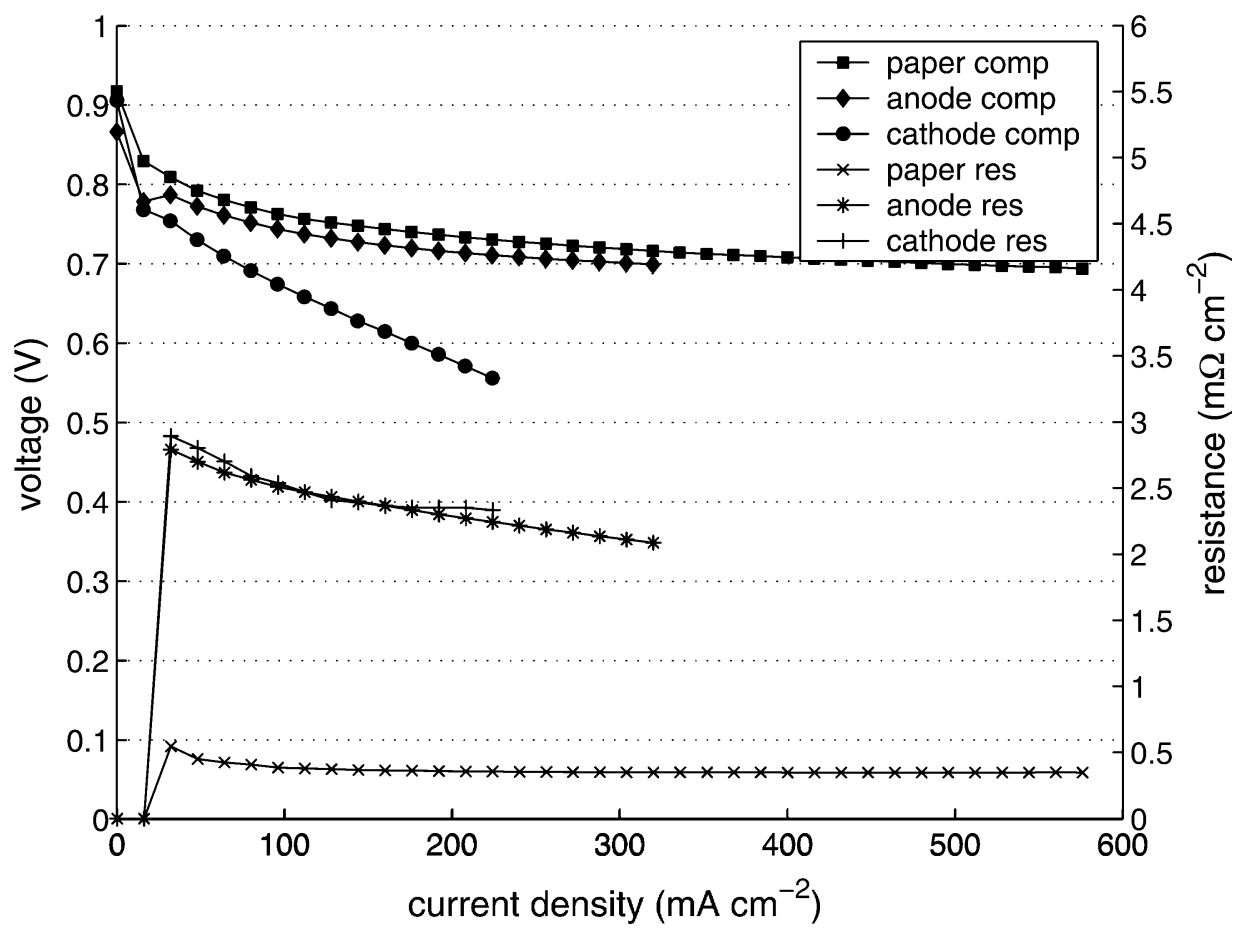

Fig. 5. The IR-compensated polarization curves and resistance curves from the measurement where both of the gas diffusion backings were carbon paper, and the measurements where other gas diffusion backing was titanium sinter: 'comp' refers to the IR-compensated polarization; 'res' refers to the resistance curves. 


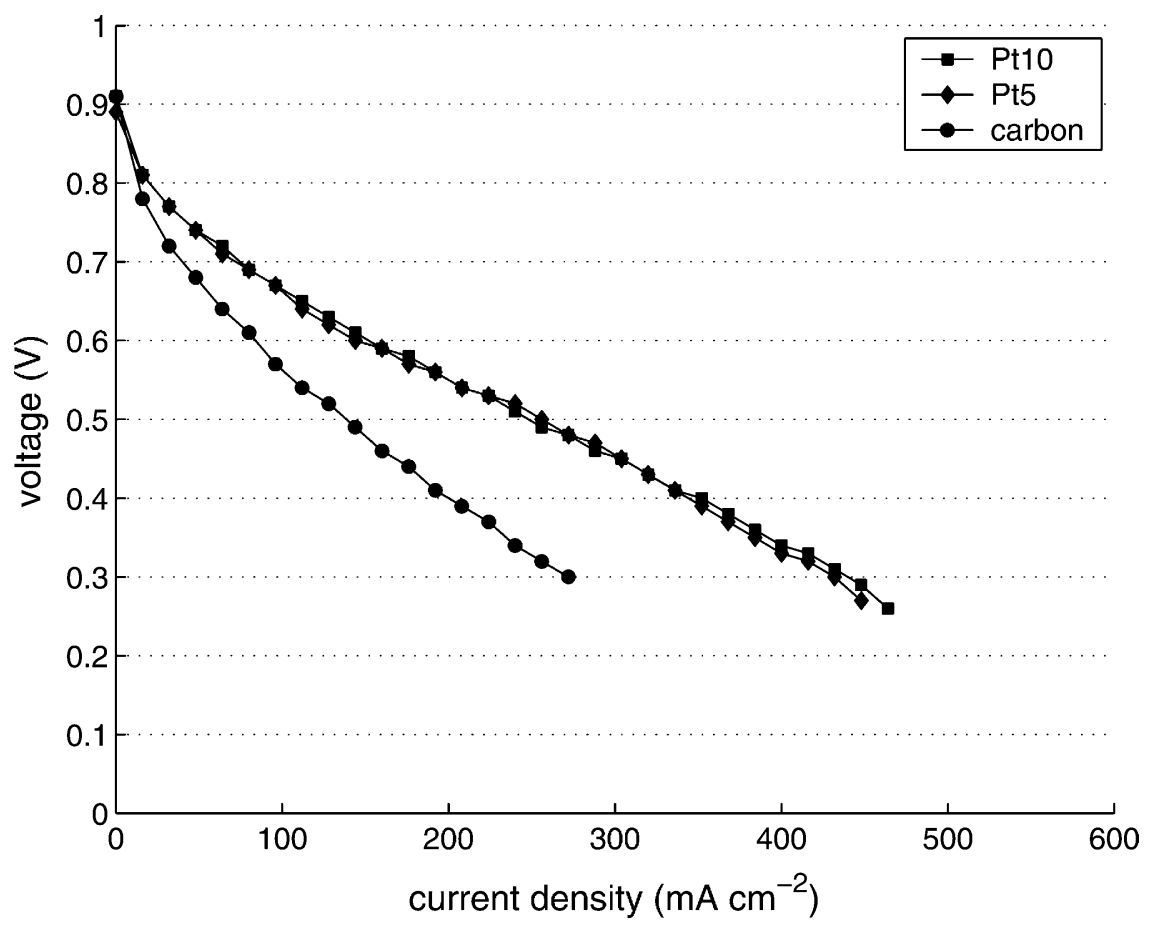

Fig. 6. The polarization curves from the measurements with platinum and carbon-coated sinters on the cathode. 'Pt10' and 'Pt5' refer to the platinum coatings of 10 and $5 \mathrm{~nm}$, and 'carbon' to the carbon coating.

Comparing Figs. 4 and 6, it can be seen that coated sinters perform somewhat better than the uncoated one. However, the performance improvement achieved with a carboncoated sinter is quite moderate, whereas sinters with platinum coatings performed significantly better. The reason for this can be seen from Fig. 7. The carbon coating has no apparent improvement on the resistance of the fuel cell with titanium sinter whereas the platinum coating reduces the resistance to less than half than the one with uncoated sinter. This implies that the contact resistance between titanium

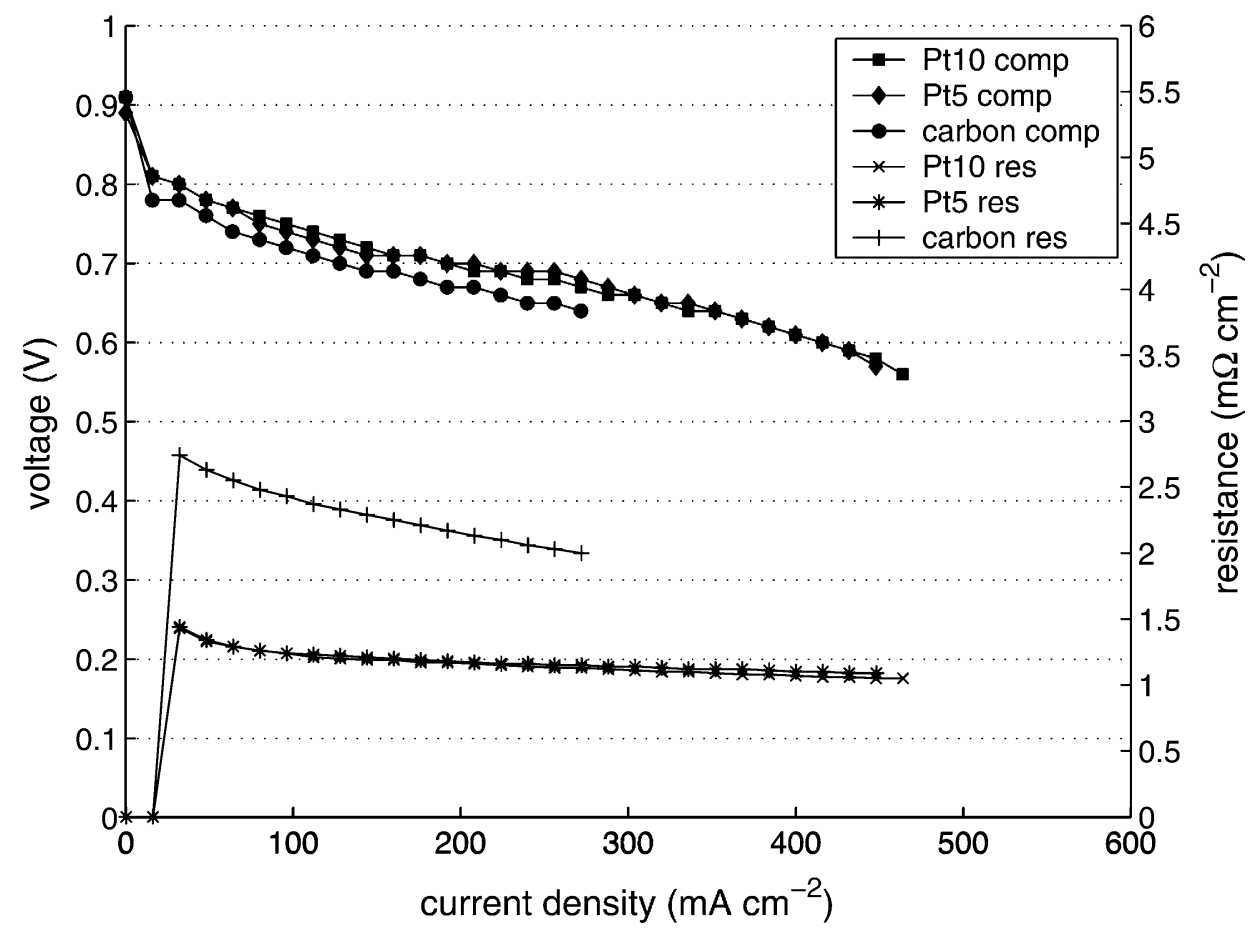

Fig. 7. The IR-compensated polarization curves and resistance curves from the measurements with platinum and carbon-coated sinters on the cathode. 
sinter and carbon is significantly higher than the one between titanium sinter and platinum.

It can be seen from the IR-compensated polarization curves in Figs. 5 and 7 that the coatings reduce the mass diffusion overpotential observed with the uncoated sinter. The coatings have probably increased the hydrophobicity of the sinter and thus enhanced the removal of excess water from the cathode increasing the active electrode area.

\section{Conclusions}

The applicability of titanium sinter as gas diffusion backing in a PEMFC was studied. The results showed that the contact resistance between the titanium sinter and MEA is quite large. This can be reduced quite efficiently with platinum coating on the surface of the sinter. The results revealed also that the sinter on the cathode side of the fuel cell increases the mass diffusion overpotential. This may be due to the insufficient removal of excess water. The coating reduced this overpotential to some extent and may have been a result of increased hydrophobicity.

The performance of the fuel cell with platinum-coated titanium sinter as gas diffusion backing was somewhat weaker than with carbon paper. However, titanium sinters may be advantageous in applications where high current densities are not necessary. This is especially the case in applications where a simplified fuel cell structure is favorable. The sinters can operate as combined gas diffusion backing/flow-field plate or the need of gas channels can be eliminated since the sinters do not need the mechanical support of the ridges. On the basis of the results, it can be assumed that the titanium sinters may also be able to operate as a direct gas diffusion path in a free-breathing fuel cell.

The price of industrially manufactured titanium sinters is approximately US $\$ 0.1 \mathrm{~cm}^{-2}$ [9]. This is comparable to the price of commercial carbon papers and cloths. However, the cost of platinum coating slightly increases the price of sinters. If the sinter is operated as combined gas diffusion backing/ flow-field plate, the affordability of sinters is significantly improved, because the need of a separate flow-field plate is eliminated. Thus, a preliminary economic analysis indicates that titanium sinters have a potential for practical use, but a more detailed economic analysis will be necessary to verify its large-scale applicability.

In further studies, the mass transport problems of titanium sinters will be examined. Temperature has an effect on the water removal, and thus it is of great interest to know how the sinters perform at different temperatures. Furthermore, the applicability of titanium sinters in free-breathing cells is yet to be ascertained.

\section{Acknowledgements}

The funds from the National Technology Agency of Finland (TEKES) and Fortum Foundation are greatly acknowledged. LabGas Instrument $\mathrm{Co}$ is acknowledged for providing the titanium sinters and SGL Technologies $\mathrm{GmbH}$ for providing the carbon paper gas diffusion backings used in the study. In addition, the authors wish to thank Sergey Novikov from the Electron Physics laboratory of Helsinki University of Technology for the platinum coatings.

\section{References}

[1] D. Chu, R. Jiang, J. Power Sources 83 (1999) 128-133.

[2] S. Morner, S.A. Klein, J. Solar Energy Eng. 123 (2001) 225-231.

[3] M. Noponen, T. Mennola, M. Mikkola, T. Hottinen, P. Lund, J. Power Sources 106 (2002) 304-312.

[4] C. Zawodzinski, M.S. Wilson, in: Proceedings of the Second International Symposium on Proton Conducting Membrane Fuel Cells, Electrochem. Soc. Proc. 98 (27) (1999) 446-456.

[5] S. Gamburzev, A.J. Appleby, J. Power Sources 107 (2002) 5-12.

[6] P.J. Mitchell, Int. Patent WO 98/52241 (1998).

[7] W.-K. Lee, C.-H. Ho, J.W. Van Zee, M. Murphy, J. Power Sources 84 (1999) 45-51.

[8] J.C. Amphlett, R.M. Baumert, R.F. Mann, B.A. Peppley, P.R. Roberge, J. Electrochem. Soc. 142 (1995) 1-8.

[9] R. Varila, CEO, LabGas Instrument Co., 29 November 2002 (private communications). 